Original

\title{
Tumorigenic Susceptibility of Catechol on the Gastric Mucosa in rasH2 Mice
}

\author{
Masaki Yamazaki ${ }^{1}$, Mitsuyoshi Moto ${ }^{1}$, Tamotsu Takizawa ${ }^{2}$, Yoko Kashida ${ }^{1}$, \\ Toshio Imai ${ }^{2}$, Kunitoshi Mitsumori ${ }^{1}$, and Masao Hirose ${ }^{2}$ \\ ${ }^{1}$ Laboratory of Veterinary of Pathology, Tokyo University of Agriculture and Technology, 3-5-8 Saiwai-cho, Fuchu-shi, \\ Tokyo 183-8509, Japan \\ ${ }^{2}$ Division of Pathology, National Institute of Health, 18-1 Kamiyoga, Setagaya-ku, Tokyo 158-8501, Japan
}

\begin{abstract}
The present study was undertaken to examine the susceptibility of catechol on the gastric mucosa of male rasH2 mice which have high susceptibility to genotoxic carcinogens. Mice were divided into 4 groups consisting of 7 to 15 per group, and given diets containing catechol at doses of $0,0.2,0.4$ or $0.8 \%$ for 26 weeks. In the pyloric mucosa of the stomach, hyperplasias of gastric mucosa were significantly increased in the groups treated with $0.4 \%$ or more catechol, along with increased proliferating cell nuclear antigen (PCNA) positive rates, but no stomach tumors were induced. In the fundic mucosa of the stomach, the incidences of atrophic fundic glands with fewer and atrophic parietal cells were significantly increased in the groups treated with $0.4 \%$ or more catechol. In the forestomach, epithelial hyperplasias of the limiting ridge were observed in 5 of 15 mice given $0.8 \%$ catechol. These results suggest that ras $\mathrm{H} 2$ mice are not susceptible to glandular stomach carcinogenesis induced by catechol, although pyloric epithelial hyperplasias and increased proliferation activity of the pyloric mucosa were induced in rasH2 mice given the higher doses of catechol. (J Toxicol Pathol 2005; 18: 1-5)
\end{abstract}

Key words: carcinogenesis, catechol, forestomach, glandular stomach, $\mathrm{rasH} 2$ mice

\section{Introduction}

The rasH2 mouse carrying a human prototype c-Ha-ras gene with its own promoter region has been widely used in many 6-month short-term carcinogenicity tests as an alternative to the traditional 2-year mouse bioassay. Approximately 3 copies of human c-Ha-ras gene encoding the Ras protein, a key molecule in the signal transduction pathway for cell proliferation, are integrated into the genome of each rasH2 mouse in tandem array ${ }^{1,2}$. It is well recognized that the rasH2 mouse is very susceptible to genotoxic carcinogens $^{3-5}$, and the major tumor target organs are the lung, forestomach, spleen and skin. In our previous study, forestomach squamous cell tumors were induced in rasH2 mice given a single injection of $N$-ethyl- $N$-nitrosourea (ENU), and up-regulation of gene expressions of the transgene, endogenous Ha-ras and N-ras, raf, Mekk2, c-fos, $j u n \mathrm{~B}$, and $\mathrm{c}-m y c$ were observed in these tumors ${ }^{6}$. These results suggest that activation of the Ras-MAPK cascade

Received: 27 October 2004, Accepted: 17 December 2004 Mailing address: Kunitoshi Mitsumori, Veterinary of Pathology, Tokyo University of Agriculture and Technology, 3-5-8 Saiwai-cho, Fuchu-shi, Tokyo 183-8509, Japan

TEL\&FAX: 81-42-367-5771

E-mail: mitsumor@cc.tuat.ac.jp following up-regulation of both human and mouse endogenous ras genes is involved in the enhanced tumorigenesis of ENU-induced forestomach tumors in rasH2 mice. However, there are no reports of glandular stomach tumors having been induced in rasH2 mice by the treatment with carcinogens targeting the glandular stomach, although forestomach tumors were induced in rasH2 mice by the treatment of $N$-methyl- $N$ '-nitro- $N$-nitrosoguanidine (MNNG), a typical genotoxic carcinogen inducing glandular stomach tumors $^{3}$. Therefore, it is unclear whether rasH2 mice are less susceptible to the glandular stomach carcinogens.

Catechol, a benzene metabolite showing equivocal mutagenicity, is a ubiquitous environmental contaminant. It is contained in cigarette smoke, wood burning smoke, hair dyes, photographic developers and certain vegetables, and small amounts of the compound itself or of its conjugates are also detected in human urine ${ }^{7-11}$. Catechol is also used in insecticides, artificial flavors and medicines. Experimentally, it has been reported that chronic oral administration of $0.8 \%$ catechol in the diet to rats for 51 weeks resulted in the induction of glandular stomach and forestomach tumors after initiation treatment with $\mathrm{MNNG}^{12}$. In addition, catechol alone, at a dietary dose of $0.8 \%$, induced adenocarcinomas and/or adenomas in the glandular stomach of $\mathrm{F} 344$ rats and $\mathrm{B} 6 \mathrm{C} 3 \mathrm{~F}_{1}$ mice of both sexes in 2- 


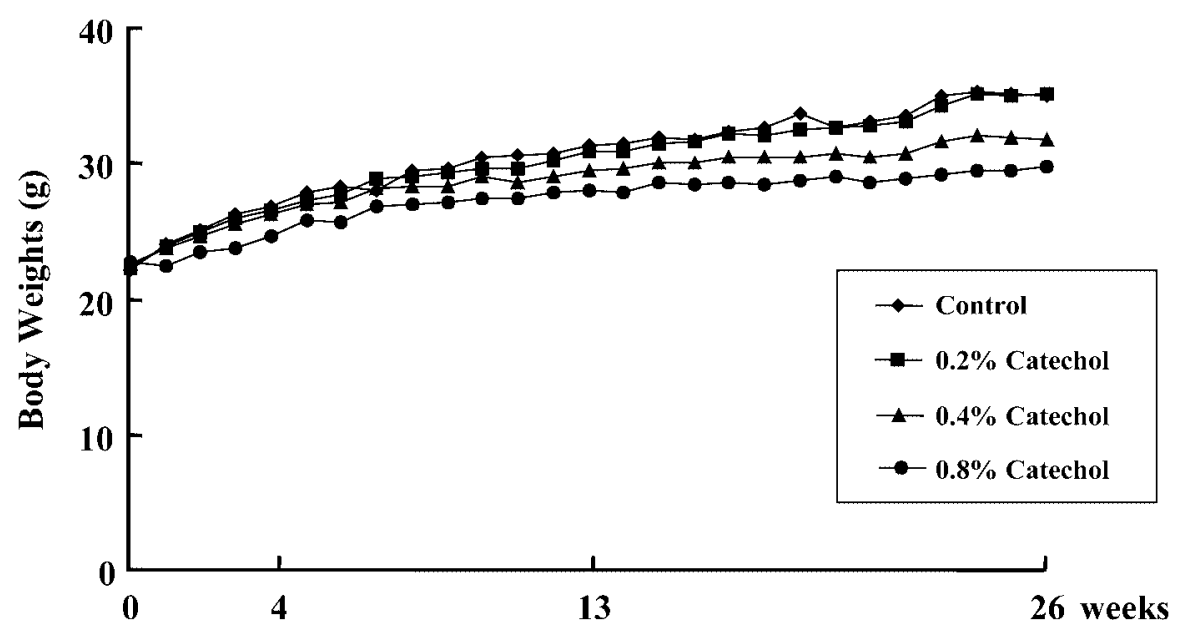

Fig. 1. Body weight changes of rasH2 mice fed catechol for 26 weeks.

year carcinogenicity studies ${ }^{13}$. Forestomach tumors were also induced in Sprague-Dawley rats by treatment with catechol at a dose of $0.8 \%$ for 2 years ${ }^{14}$. Based on these reports, we considered that catechol has tumorigenic potential to the stomach.

In the present study, to investigate the tumorigenic susceptibility on the gastric mucosa of rasH2 mice, chronic treatment of catechol for 26 weeks was performed.

\section{Materials and Methods}

\section{Animal and chemicals}

Male CB6F1-Tg-rasH2 mice, aged 6 weeks, were purchased from CLEA Japan, Inc. (Tokyo, Japan). All rasH2 mice were housed in polycarbonate cagneko es with white paper chips under barrier system conditions (room temperature, $23 \pm 2^{\circ} \mathrm{C}$; relative humidity, $55 \pm 5 \%$; 12 hours light and dark cycle). Catechol (CAS: 120-80-9, purity > 99\%) was purchased from Wako Pure Chemical Industries, Ltd. (Osaka, Japan).

\section{Treatment}

After 2 weeks acclimatization, rasH2 mice were divided into 4 groups consisting of 7 to 15 animals per group, and treated with dietary catechol at doses of $0,0.2$, 0.4 or $0.8 \%$ for 26 weeks. Body weight and food consumption were measured once a week. After 26 weeks, all animals were euthanatized by deep ether anesthesia and necropsied for histopathological examination.

\section{Histopathological examination}

At necropsy, the stomach, esophagus, tongue, trachea, lung, thyroid, thymus, heart, aorta, liver, kidneys, adrenals, spleen and other gross lesions were removed and fixed in $10 \%$ neutral buffered formalin. In order to fix the stomach well, formalin was injected from the upper point of the duodenum into the stomach with a ligated esophagus. After 3 min, the great curvature side of stomach was cut, and was
Table 1 Incidences of Pathological Changes of the Stomach in ras $\mathrm{H} 2$ Mice Fed Catechol for 26 weeks

\begin{tabular}{ccccc}
\hline $\begin{array}{c}\text { Doses } \\
\text { No. of animals }\end{array}$ & Cont. (0\%) & $0.2 \%$ & $0.4 \%$ & $0.8 \%$ \\
\cline { 2 - 5 } & 7 & 13 & 15 & 15 \\
\hline $\begin{array}{l}\text { Forestomach } \\
\text { Papilloma } \\
\quad \text { Squamous cell hyperplasia }\end{array}$ & 0 & 0 & 0 & $5^{\text {a) }}$ \\
$\begin{array}{c}\text { Glandular stomach } \\
\text { Fundic mucosa } \\
\quad \text { Atrophy }\end{array}$ & & & & \\
$\quad \begin{array}{l}\text { Pyloric mucosa } \\
\text { Hyperplasia }\end{array}$ & 0 & 4 & $13^{* *}$ & $15^{* *}$ \\
\hline
\end{tabular}

$* * \mathrm{p}<0.01$ by Fischer's exact probability test.

a) Detected at limiting ridge.

placed in formalin for further fixing. For histopathological analysis, all tissues including these of the stomach were embedded in paraffin, sectioned, and stained with hematoxylin-eosin (H-E), routinely. Immunohistochemical stain using a proliferating cell nuclear antigen (PCNA) antibody (DakoCytomation Co. Ltd., Kyoto, Japan) was performed on the sections of mucosa in the glandular stomach. PCNA-positive cells were counted in the cells of 50 gastric pits (200-500 cells) of fundic and pyloric glands in the glandular stomach, to calculate the rate of positive cells per pit.

\section{Results}

There were no differences in the deaths, survival rate and food consumption between the groups treated with catechol and the control group (data not shown). Significant depression of body weight gain was observed in the $0.4 \%$ and $0.8 \%$ dietary catechol groups, as compared with the control group (Fig. 1).

Histopathologically, squamous cell hyperplasias in the limited ridge of the forestomach were observed in 5 of 15 


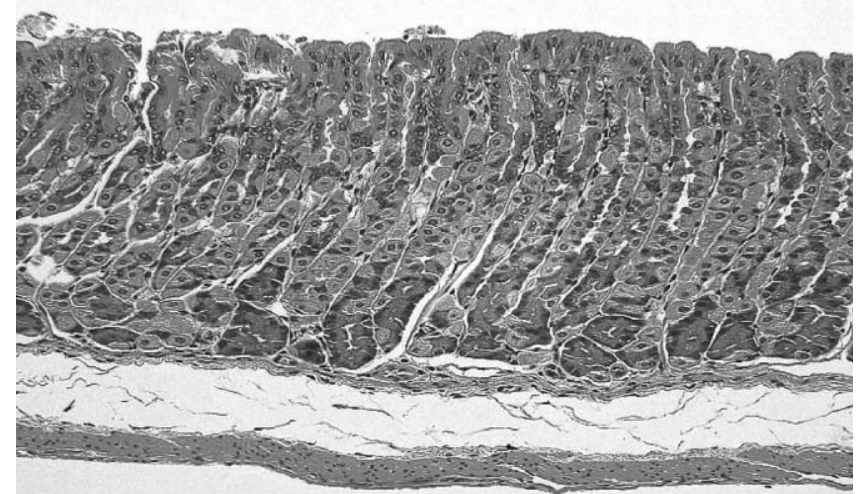

A

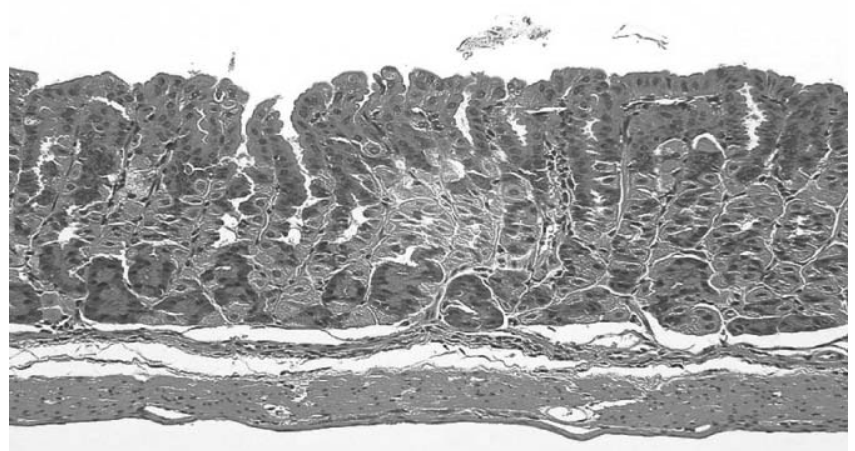

B
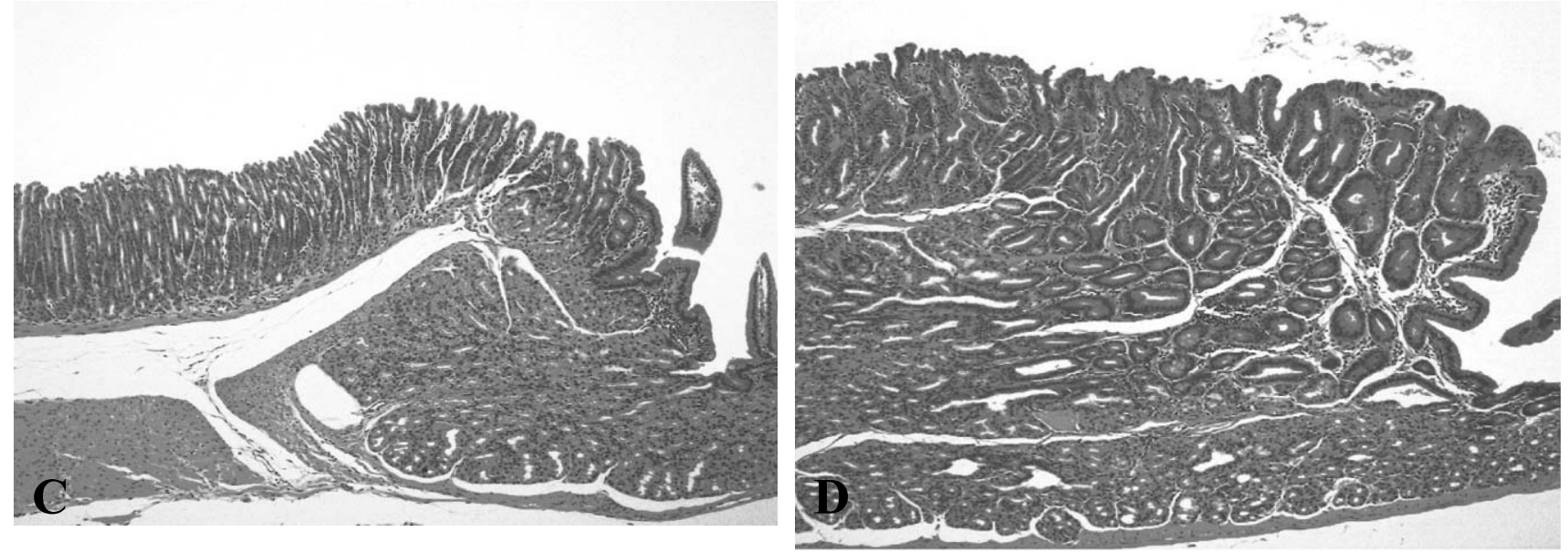

Fig. 2. Histopathology of the fundic (A and B) and pyloric (C and D) mucosa of the glandular stomach. A and C: Control group. B and D: $0.8 \%$ Catechol treated group. Atrophic fundic mucosa with fewer and atrophic parietal cells was observed (B). Hyperplasias of pyloric mucosa were observed (D). H-E, $\times 100$.

males of the $0.8 \%$ catechol group (Table 1 ). In fundic mucosa of the glandular stomach, atrophic fundic glands with fewer and atrophic parietal cells were observed in all treated groups, however, the incidences were significantly increased in the groups treated with $0.4 \%$ or more catechol (Table 1, Fig. 2A, B). In the pyloric mucosa, although no neoplastic lesions occurred in any group, mucosa hyperplasias with inflammatory cellular infiltration, especially at the edge of pyloric region, were observed in almost all the animals of the groups treated with $0.4 \%$ or more catechol (Table 1, Fig. 2C, D). Immunohistochemical examinations indicated that the PCNA positive rates of the fundic mucosa in all groups were significantly lower than that of the control group. Regarding pyloric mucosa, the PCNA positive rate dose-dependently increased in the treated groups, and significant differences compared to that of control groups were observed in the groups treated with $0.4 \%$ or more catechol (Fig. 3).

Other than the stomach, lung adenoma were sporadically observed in 0 to 2 animals in the test groups, but no significant increase in the incidence was found in these groups as compared to the control group.

\section{Discussion}

In genotoxicity studies of catechol, negative results were obtained in the Ames assay with or without S9 mix ${ }^{15}$, Escherichia coli DNA polymerase assay, and the HeLa DNA synthesis test on Chinese hamster V79 cells, but the result of the micronucleus test in mice was positive ${ }^{7}$. In carcinogenicity studies of catechol in which 30 male and female $\mathrm{F} 344$ rats and $\mathrm{B} 6 \mathrm{C} 3 \mathrm{~F}_{1}$ mice were treated with $0.8 \%$ catechol powdered in diet for 104 weeks, adenomas of the glandular stomach were found in all rats and the majority of mice $^{13}$. There was also a report that the treatment with dietary catechol at a dose of $0.8 \%$ for 51 weeks after initiation with MNNG caused epithelial tumors in the glandular stomach and forestomach of rats ${ }^{12}$. Catechol enhanced the incidence of carcinomas in the tongue and esophagus after $\mathrm{N}$-methyl- $\mathrm{N}$-amylnitrosamine (MNAN) initiation ${ }^{16}$. It has been generally considered that primary cell proliferation and regenerative cell proliferation due to cytotoxicity might be important factors for carcinogenesis of non-genotoxic carcinogens ${ }^{13,17-20}$. Regarding the possible mechanism of the glandular stomach carcinogenesis of 


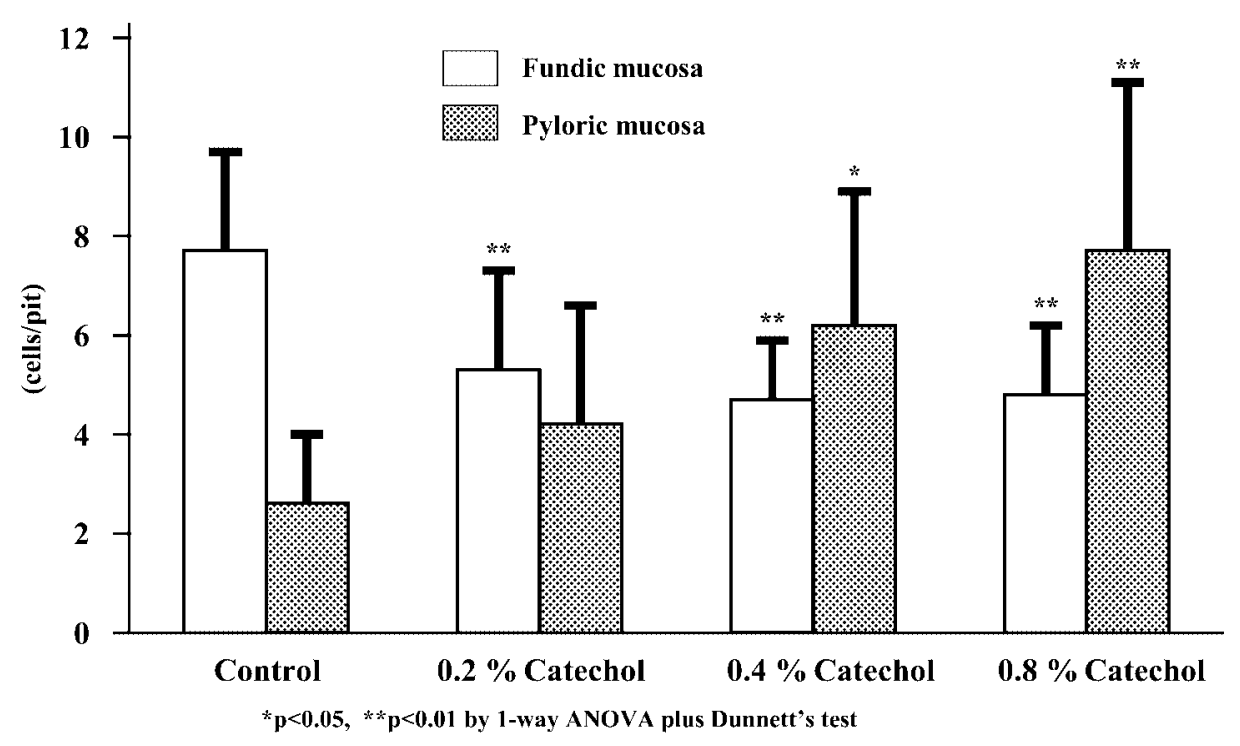

Fig. 3. PCNA-positive rate (cells/pit) in glandular stomach.

catechol, a secondary effect resulting from regeneration following tissue damage by catechol is considered to be the mechanism, because proliferative lesions were observed after the onset of damage to the stomach mucosa in timecourse histopathological examinations ${ }^{21}$. Therefore, the repeated degeneration and regeneration of pyloric mucosa caused by catechol may result in the enhancement of spontaneous mutation followed by the occurrence of stomach tumors in long-term treatment with catechol. Additionally, catechol was re-evaluated by the International Agency for Research on Cancer (IARC), and it was classified as a group 2B carcinogen which is a possible carcinogen for humans ${ }^{22}$. Taking into account this information, it is generally considered that although catechol itself may have some genotoxic potential, its mode of action of carcinogenicity on the glandular stomach epithelium is non-genotoxic.

In the present study, catechol induced neither neoplastic lesions nor hyperplasias in the pyloric mucosa of the glandular stomach of rasH2 mice. This means that either rasH2 mice are less susceptible to glandular stomach carcinogenesis or the treatment period is not long enough to induce of stomach tumors. In rasH2 mice, it has been reported that forestomach papillomas and/or squamous cell carcinomas were induced by treatment with $\mathrm{N}, \mathrm{N}$ diethylnitrosamine (DEN) ${ }^{3}$, 4-hydroxyaminoquinolone-1oxide (4-HAQO) ${ }^{23}$, melphalan ${ }^{23}, \mathrm{MNNG}^{3}, N$-methyl- $N$ nitrosourea $(\mathrm{MNU})^{3}$, phenacetin $^{23}, 4,4^{\prime}$-thiodianiline ${ }^{23}$, thiotepa ${ }^{23}$, vinyl carbamate ${ }^{4}$ and 4-vinyl-1-cyclohexene diepoxide ${ }^{23}$. On the other hand, reports dealing with glandular stomach carcinogenesis in rasH2 mice are extremely rare, and there is only one report that MNNG, a genotoxic carcinogen induced glandular stomach tumors in rats $^{24}$, and it did not induce any tumors in the glandular stomach of rasH2 mice ${ }^{25}$. Therefore, $\mathrm{rasH} 2$ mice appear to be less sensitive to glandular stomach carcinogenesis.
However, it is premature to reach such a conclusion, since further longer-term experiments extending from 6 months to one year are necessary to clarify the carcinogenic susceptibility of the glandular stomach of rasH2 mice.

With respect to the other models of transgenic mice or knockout mice that can be used as alternatives to the traditional 2-year mouse bioassay, heterozygous $p 53$ knockout $[p 53(+/-)]$ mice are also widely used. Ohgaki et $a l$. reported that glandular stomach adenocarcinomas were induced in 2 of 8 homozygous $p 53$ mice $[p 53(-/-)$ mice] that were subjected to gastric intubation of $5 \mu \mathrm{g} / \mathrm{g}$ body weight MNU 3 times/week for 5 weeks and were sacrificed in extremis before week $50^{26}$. In their study, such adenocarcinomas were induced both in $p 53(+/-)$ and $p 53$ wild-type $(+/+)$ mice, that were subjected to the same treatment and were reared without any treatment up to 50 weeks. The development of the adenocarcinomas invading into the submucosa occurred only in $p 53(+/-)$ mice but not in $p 53(+/+)$ mice, and the results of their study suggest that $p 53(-/-)$ and $p 53(+/-)$ mice are more susceptible to the intragastric application of MNU than $p 53(+/+)$ mice. In their other study of $p 53(-/-)$ and $p 53(+/-)$ mice, these animals were given water containing $30 \mathrm{ppm}$ MNU for 10 weeks (1 week on and 1 week off) and sacrificed at week 15 . Adenomas and adenocarcinomas of the glandular stomach were induced in both these knockout mice and the incidences of them in $p 53(-/-)$ mice were significantly greater than in $p 53(+/-)$ mice $^{27}$. These findings may suggest that $p 53(+/-)$ and $p 53(-/-)$ mice are much more susceptible to glandular stomach carcinogenesis than rasH2 mice.

In summary, the results of the present study suggest that rasH2 mice are not susceptible to glandular stomach carcinogenesis induced by catechol, although pyloric epithelial hyperplasias and increased proliferation activity of the pyloric mucosa were induced in rasH2 mice given high doses of catechol. Further studies are necessary to determine 
whether rasH2 mice are inappropriate for the detection of carcinogens targeting the glandular stomach.

\section{References}

1. Saitoh A, Kimura M, Takahashi R, Yokoyama M, Nomura T, Izawa M, Sekiya T, Nishimura S, and Katsuki M. Most tumors in transgenic mice with human c-Ha-ras gene contained somatically activated transgenes. Oncogenes. 5: 1195-1200. 1990.

2. Suemizu H, Muguruma K, Maruyama C, Tomisawa M, Kimura M, Hioki K, Shimozawa N, Ohnishi Y, Tamaoki N, and Nomura T. Transgene stability and features of rasH2 mice as an animal model for short-term carcinogenicity testing. Mol Carcinog. 34: 1-9. 2002.

3. Yamamoto S, Mitsumori K, Kodama Y, Matsunuma N, Manabe S, Okamiya H, Suzuki H, Fukuda T, Sakamaki Y, Sunaga M, Nomura G, Hioki K, Wakana S, Nomura T, and Hayashi Y. Rapid induction of more malignant tumors by various genotoxic carcinogens in transgenic mice harboring a human prototype c-Ha-ras gene than in control nontransgenic mice. Carcinogenesis. 17: 2455-2461. 1996.

4. Mitsumori K, Wakana S, Yamamoto S, Kodama Y, Yasuhara K, Nomura T, Hayashi Y, and Maronpot RR. Susceptibility of transgenic mice carrying human prototype c-Ha-ras gene in a short-term carcinogenicity study of vinyl carbamate and ras gene analysis of the induced tumors. Mol Carcinog. 20: 298-307. 1997.

5. Maruyama C, Tomisawa M, Wakana S, Yamazaki H, Kijima H, Suemizu H, Ohnishi Y, Urano K, Hioki K, Usui T, Nakamura M, Tsuchida T, Mitsumori K, Nomura T, Tamaoki N, and Ueyama Y. Overexpression of human H-ras transgene is responsible for tumors induced by chemical carcinogens in mice. Oncol Rep. 8: 233-237. 2001.

6. Okamura M, Sumida K, Muto T, Kashida Y, Machida N, Watanabe T, and Mitsumori K. Analysis of gene expression profiles of forestomach tumors in rasH2 mice initiated with $N$-ethyl- $N$-nitrosourea. Arch Toxicol. 2004; in press.

7. Anonymous. Final report on the safety assessment of hydroquinone and pyrocatechol. J Am Coll Toxicol. 5: 123165. 1986.

8. International Agency for Research on Cancer. IARC Monographs on the Evaluation of Carcinogenic Risk of Chemicals to Humans, Vol. 15. Lyon. 155-175. 1997.

9. International Agency for Research on Cancer. IARC Monographs on the Evaluation of Carcinogenic Risk of Chemicals to Humans, Vol. 38. Lyon. 83-126. 1985.

10. Raff $\mathrm{R}$ and Ettling BV. Hydroquinone, resorcinol and pyrocatechol. In: Kirk RE and Othmer DF (eds), Encyclopedia of Chemical Technology. John Wiley and Sons Inc., New York, Vol. 11. 462-492. 1996.

11. Rahn W and Koning WA. GS/MS investigation of the constituents in a diethyl ether extract of an acidified roast coffee infusion. J High Resolut Chromatogr chromatogr Commun. 1: 69-71. 1978.

12. Hirose M, Fukushima S, Kurata Y, Tsuda H, Tatematsu M, and Ito $\mathrm{N}$. Modification of $N$-methyl- $N$ '-nitrosoguanidineinduced forestomach and glandular stomach carcinogenesis by phenolic antioxidants in rats. Cancer Res. 48: 5310-5315. 1988.

13. Hirose M, Fukushima S, Tanaka H, Asakawa E, Takahashi
$\mathrm{S}$, and Ito N. Carcinogenicity of catechol in F344 rats and

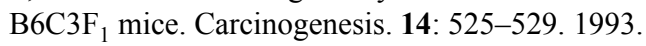

14. Tanaka H, Hirose M, Hagiwara A, Imaida $K$, shirai $T$, and Ito N. Rat strain differences in catechol carcinogenicity to the stomach. Food Chem Toxicol. 33: 93-98. 1993.

15. Howorth S, Lawlor T, Mortelmans K, Speck W, and Zeiger E. Salmonella mutagenicity test results for 250 chemicals. Environmental Mutagenesis. Suppl 1: 3-142. 1983.

16. Yamaguchi S, Hirose M, Fukushima S, Hasegawa R, and Ito N. Modification by catechol and resorcinol of upper digestive tract carcinogenesis in rats treated with methyl- $N$ amylnitrosamine. Cancer Res. 49: 6015-6018. 1989.

17. Tanaka H, Hirose M, Hagiwara A, Imaida K, Shirai T, and Ito N. Rat Strain Differences in Catechol Carcinogenicity to the Stomach. Food Chem Toxicol. 33; 93-98. 1995.

18. Furihata C, Hatta A, and Matsushima T. Inductions of ornithine decarboxylase and replicative DNA synthesis but not DNA single strand scission or unscheduled DNA synthesis in the pyloric mucosa of rat stomach by catechol. Jpn J Cancer Res. 80: 1052-1057. 1989.

19. Kawabe M, Takaba K, Yoshida Y, and Hirose M. Effects of combined treatment with phenolic compounds and sodium nitrite on two-stage carcinogenesis and cell proliferation in the rat stomach. Jpn J Cancer Res. 85: 17-25. 1994.

20. Ohshima H, Friesen M, Malaveille C, Brouet I, Hautefeuille $\mathrm{A}$, and Bartsch H. Formation of directacting genotoxic substances in nitrosated smoked fish and meat products: identification of simple phenolic precursors and phenyldiazonium ions as reactive products. Food Chem Toxicol. 27: 193-203. 1989.

21. Hirose M, Hakoi K, Takahashi S, Hoshiya T, Akagi K, Lin C, Saito K, Kaneko H, and Shirai T. Sequential morphological and biological changes in the glandular stomach induced by oral administration of catechol to male F344 rats. Toxicol Pathol. 27: 448-455. 1999.

22. International Agency for Research on Cancer. IARC Monographs on the Evaluation of Carcinogenic Risks to Human, Vol. 71. Lyon. 433-451. 1999.

23. International Agency for Research on Cancer. IARC Monographs on the Evaluation of the Carcinogenic Risks to Humans, Vol. Suppl 7. Lyon. 248-250. 1987.

24. Yamamoto S, Urano $\mathrm{K}$, and Nomura T. Validation of transgenic mice harboring the human prototype c-Ha-ras gene as a bioassay model for rapid carcinogenicity testing. Toxicol Lett. 102-103: 473-478. 1998.

25. Yamamoto S, Mitsumori K, Kodama Y, Matsunuma N, Manabe S, Okamiya H, Suzuki H, Fukuda T, Sakamaki Y, Sunaga M, Nomura G, Hioki K, Wakana S, Nomura T, and Hayashi Y. Rapid induction of more malignant tumors by various genotoxic carcinogens in transgenic mice harboring human prototype c-Ha-ras gene than in control nontransgenic mice. Carcinogenesis. 17: 2455-2461. 1996.

26. Ohgaki H, Fukuda M, Tohma Y, Huang H, Stoica G, Tatematsu M, and Donehower LA. Effect of intragastric application of $N$-methylnitrosourea (MNU) in $p 53$ knockout mice. Mol Carcinog. 28: 97-101. 2000.

27. Yamamoto M, Tsukamoto T, Sakai H, Shirai N, Ohgaki H, Furihata C, Donehower LA, Yoshida K, and Tatematsu M. p53 knockout mice $(-/-)$ are more susceptible than $(+/-)$ or $(+/+)$ mice to $N$-methyl- $N$-nitrosourea stomach carcinogenesis. Carcinogenesis. 21: 1891-1897. 2000. 